\title{
La fase preliminar del nuevo proceso de nulidad
}

\section{The Preliminary Phase of the New Nullity Proceedings}

\section{Gerardo NÚÑEZ}

Profesor Adjunto de Derecho Procesal Canónico

Universidad de Navarra. Facultad de Derecho Canónico orcid 0000-0003-3417-3033

gnunez@unav.es

Resumen: Con la reforma del proceso de nulidad matrimonial del m.p. Mitis ludex, el Romano Pontífice ha dispuesto la institución de un servicio pastoral diocesano para ayudar a los fieles con dificultades en su matrimonio. Los fines de este servicio pastoral son múltiples, dependiendo de la situación matrimonial de los fieles que acuden al mismo: ofrecer acompañamiento espiritual; realizar una mediación para intentar superar la crisis matrimonial; convalidar el matrimonio si fuera posible; orientar a los cónyuges hacia la viabilidad de un proceso de nulidad matrimonial. La estructura y personal de este servicio será variado con arreglo a cada diócesis. Se aconseja a la Conferencia Episcopal redactar un Vademécum de apoyo para dar una unidad a este servicio.

Palabras clave: Indagación prejudicial, Servicio pastoral, Vademécum.
Abstract: As part of the reform of the marriage annulment process stipulated in Motu Proprio Mitis Iudex, the Pope has ordered the establishment of a diocesan pastoral service to help the faithful who experience difficulties in their marriage. The functions of this pastoral service are manifold, depending on the marital status and needs of the faithful: to offer spiritual accompaniment; to mediate a possible solution to the marital crisis; to validate the marriage if possible; to guide spouses on the feasibility of a marriage annulment process. The structure and staff of this service will vary from diocese to diocese. Episcopal Conferences are encouraged to draw up a Vademecum that will ensure the integrity of such services.

Keywords: Preliminary Inquiry, Pastoral Service, Vademecum. 


\section{Introducción. Algunos ElEMENTOS INSPIRAdORES DE LA REFORMA}

E s de todos conocido que tras los Sínodos celebrados sobre la familia y la nueva regulación canónica -m.p. Mitis Iudex Dominus Iesus y sus Reglas Procesales ${ }^{1}$ - se ha puesto de manifiesto los cambios relacionados con el matrimonio, que constituyen un desafío para la evangelización de la Iglesia: parejas de hecho que no acceden al matrimonio, uniones entre personas del mismo sexo, matrimonios mixtos, familia monoparental, cultura de la falta de compromiso, pluralismo relativista en la concepción del matrimonio, elevada cifra de divorcios y separaciones ${ }^{2}$, etc. Ello plantea un reto en la pastoral matrimonial para afrontar la situación actual, así como una necesidad de mayor coordinación entre los agentes pastorales familiares.

En este contexto se ha deseado resaltar la labor que el Obispo y los párrocos deben realizar en todo momento, y siempre coordinados en la pastoral diocesana matrimonial, cuya regulación está recogida en la fase prejudicial señalada en los arts. 1-5 RP. Esta normativa se centra en la fase problemática de un matrimonio: matrimonios en crisis, separados o divorciados, a los que se desea ayudar pastoralmente y, si hubiese indicios de nulidad, realizar un estudio para ver si convendría plantearla judicialmente. Es en estos supuestos donde las Reglas se fijan principalmente y donde radica su novedad.

Posteriormente a esta legislación, en enero del 2016 la Rota Romana ha enviado a todos los Obispos del mundo un Subsidio ${ }^{3}$ para ayudarles a poner en práctica estas normas. Aunque se estudiará más detenidamente, uno de los primeros pasos que los Obispos están llamados a realizar es la creación de un servicio de información, de asesoría y de mediación vinculado con la pastoral familiar, que podrá acoger a las personas con ocasión de la investigación preliminar al proceso matrimonial ${ }^{4}$, con el fin de ayudar a superar las crisis conyugales; recoger los elementos útiles para la causa de nulidad; y en su caso, ayudar a confeccionar el escrito de demanda para presentar ante el tribunal ${ }^{5}$. Todo ello abre

\footnotetext{
${ }^{1}$ En adelante RP.

2 Para unos datos numéricos y estadísticos sobre la celebración de nuevos matrimonios y las rupturas familiares, tanto en España como en varias partes del mundo, puede verse J. A. NIEVA GARCÍA, Reforma del proceso canónico para la declaración de nulidad del matrimonio y pastoral de los fieles divorciados y vueltos a casar, Universidad San Dámaso, Madrid 2015, 43-60.

3 Tribunal Apostólico de la Rota Romana, Subsidio aplicativo del Motu pr. Mitis Iudex Dominus Iesus, Ciudad del Vaticano, enero 2016 (en adelante, Subsidio).

${ }^{4}$ Cfr. ibid., 13.

${ }^{5}$ Cfr. ibid., 16.
} 
nuevos horizontes, sin que se limite esta acción pastoral-jurídica a la certificación de la existencia o no de la validez de los matrimonios, lo que constituiría un reduccionismo a su potencialidad y se desperdiciaría una oportunidad para una verdadera renovación en la pastoral del sacramento del matrimonio. Tanta experiencia adquirida por los mediadores matrimoniales, y por los jueces eclesiásticos, debería tener un cauce que revierta a la pastoral matrimonial ordinaria: pensamos que de esta manera se podrá afrontar la frágil concepción que tienen algunos cristianos de la fidelidad al vínculo matrimonial (por factores antropológicos), que hace que accedan al sacramento del matrimonio sin la adecuada formación y capacitación para dar un consentimiento coherente con su fe $\mathrm{f}^{6}$.

La doctrina ha remarcado que la finalidad de la reforma no se agota simplemente en hacer más agiles y accesibles los procesos de nulidad matrimonial, sino que busca una conversión pastoral de las estructuras judiciales así como la necesidad de integración de éstas en la pastoral familiar diocesana ${ }^{7}$. Es decir, esta conversión pasa por poner la familia en el centro de la pastoral de la Iglesia, e incorporar a esta pastoral familiar una serie de criterios-principios renovados, también desde un punto de vista jurídico. Entre estos criterios-principios que ha señalado algún autor ${ }^{8}$, coincido con él en que se debería atender a los siguientes:

1. Principio de «información», de modo que los fieles tengan noticia y conocimiento fundados de la realidad de los procesos de nulidad, de su naturaleza declarativa, de las condiciones de acceso a los mismos?.

\footnotetext{
${ }^{6}$ La nueva regulación supone un reto para la Iglesia en su estructura parroquial y diocesana. No puede quedarse en una simple labor previa de «exponer unos contenidos mínimos» en los cursillos prematrimoniales previos a la celebración del sacramento, ni tampoco en un constatar y ver la destrucción de muchos matrimonios cristianos porque no se ha sabido apoyarlos, no sólo en los momentos de dificultad, sino a lo largo de su desarrollo vital. Un reto que habla de la verdadera vocación cristiana en el matrimonio.

7 «Esta oportuna "llamada a la conversión" -con su insistencia en la intrínseca dimensión pastoral del proceso y del mismo tribunal eclesiástico, y en la conveniencia de una mayor implicación y coordinación entre la actuación del tribunal eclesiástico y las estructuras de la pastoral familiar diocesana- constituye, a mi juicio, la aportación fundamental, de fondo, de esta reforma procesal, y la clave para comprender el espíritu que la inspira, espíritu que deberá actuar como criterio general de interpretación de las novedades legislativas positivas»: C. PEÑA, Agilización de los procesos canónicos de nulidad matrimonial: de las propuestas presinodales al motu proprio Mitis Iudex Dominus Iesus y retos pendientes tras la reforma, Ius Canonicum 56 (2016) 49-50.

${ }^{8}$ Cfr. C. Morán, Retos de la reforma procesal de la nulidad del matrimonio, Ius Canonicum 56 (2016) 13-16.

9 «Será, por tanto, necesario poner a disposición de las personas separadas o de las parejas en crisis, un servicio de información, de consejo, de mediación, ligado a la pastoral familiar, que podrá también acoger a las personas de cara a la investigación previa al proceso matrimonial (cfr. MI, arts. 2-3)»: Relatio Finalis aprobada por la Asamblea Ordinaria del Sínodo el 24 de octubre de
} 
2. Principio de «acompañamiento» que ayude al discernimiento jurídicopastoral del verdadero estado personal, y que expresamente se menciona en el Proemio del Mitis Iudex, donde se justifica el recurso al proceso y la reforma del mismo en estos términos: «la caridad y la misericordia exigen, por tanto, que la propia Iglesia, como madre, se acerque a estos hijos suyos que se consideran separados de ella»; este «acompañamiento en el ámbito jurídico del otro» debe hacerse en los diversos niveles de la pastoral familiar y por distintos agentes, también por parte de los tribunales eclesiásticos.

3. Principio de «coordinación» entre los distintos agentes y niveles de la pastoral familiar, de modo que se verifique una presencia real-efectiva de los expertos en las disciplinas jurídico-matrimoniales y de quienes ejercen la actividad judicial en la Iglesia. Para que todo ello se pueda concretar, además de trabajar en el plano del diseño pastoral -fundamentalmente a nivel diocesano, pero también a otros niveles-, habrá que atender a la formación, y habrá que buscar personas idóneas que puedan participar en estos servicios, que podrán muy bien ser encomendados a laicos.

Con estos criterios -información, acompañamiento y coordinación-, en los diversos ámbitos de la pastoral se podrá hacer efectivo este primer gran reto de la reforma del proceso de nulidad: la transformación de las estructuras pastorales-familiares, también de las estructuras jurídico-pastorales; para su efectiva realización, resultará clave la actuación del Obispo diocesano ${ }^{10}$.

La puesta en marcha de la reforma dependerá de las circunstancias concretas en cada diócesis y, todo ello, se podrá desplegar en el ámbito de la pastoral ordinaria, de la pastoral familiar y de la pastoral judicial. En resumidas cuentas, como ha apuntado uno de los redactores ${ }^{11}$ del m.p., la idea de fondo es

2015 , n. 82. En la práctica requerirá una disposición para atender las necesidades por parte del Obispo traducidas en diversas actuaciones: algunas de ellas pueden verse en C. MORÁN, El proceso brevior ante el Obispo diocesano, en M. E. Olmos OrTEga (ed.), Procesos de nulidad matrimonial tras las reforma del papa Francisco, Dykinson, Madrid 2016, 134.

$10 \ll$ El motu proprio anima a una mayor vinculación e interrelación, bajo la dirección del Obispo diocesano, entre el tribunal eclesiástico y las estructuras pastorales diocesanas, proponiendo establecer estructuras estables de acompañamiento pastoral, de mediación y de orientación que puedan asesorar a los fieles separados o divorciados en el planteamiento de su caso y puedan contribuir -en la llamada investigación prejudicial- a recoger la prueba disponible (RP, arts. 25), de modo que, una vez presentada la demanda, el proceso discurra con la mayor rapidez posible»: C. PeÑA, Agilización de los procesos..., cit., 53.

${ }^{11}$ Cfr. M. J. Arroba Conde, La pastoral judicial y la preparación de la causa en el Motu Proprio «Mitis Iudex Dominus Iesus», en M. E. Olmos OrTega (ed.), Procesos de nulidad matrimonial tras las reforma del papa Francisco, Dykinson, Madrid 2016, 71-73. 
conseguir una mayor presencia del servicio especializado que ofrecen los tribunales, no sólo informando y orientando a los que vienen a pedirlo, sino saliendo al encuentro de aquellos fieles que pudieran necesitar la atención del servicio judicial especializado; por otra parte, también se requerirá una mayor presencia de los operadores de la justicia en la pastoral diocesana de ámbito familiar: no puede ser que no se tenga en cuenta en la pastoral familiar a los especialistas en esta actividad jurídico-matrimonial ${ }^{12}$; $y$, por otra parte, el acompañamiento pastoral que sigue al servicio judicial prestado, deberá seguir proporcionando a los cónyuges tanto si hubo sentencia negativa como afirmativa de la nulidad.

Comparto este análisis, que debe ser el fondo que subyace en todo lo que es la fase prejudicial o pastoral, pero me parece que esta conversión no debería quedarse reducida simplemente a la atención pastoral y técnico jurídica de un grupo más o menos amplio de fieles, sino que debe estar englobada en la pastoral familiar: desde los cursos de preparación al matrimonio, cursos de orientación familiar de recién casados y primeros años de matrimonio, orientación médica (también psicológica) a los cónyuges, posible mediación en conflictos matrimoniales, atención pastoral a fieles en situaciones de dificultad matrimonial (separación, divorcio) y, como es lógico, el asesoramiento jurídico conveniente de convalidación del matrimonio o de posibilidades de introducir una causa de nulidad. En definitiva, la implantación por parte del Obispo de esta fase prejudicial o pastoral no se trata de algo estático y puntual al presentarse algún fiel separado o divorciado que desea un asesoramiento jurídico sobre la validez de su matrimonio ${ }^{13}$, sino de una labor dinámica más o menos intensa en la atención pastoral de los matrimonios ${ }^{14}$.

${ }^{12} \mathrm{El}$ art. $2 \mathrm{RP}$ invita a realizar una pastoral matrimonial diocesana unitaria, lo cual no podrá conseguirse sin la participación de quienes se dedican a este ministerio judicial.

13 «Teniendo en cuenta la imagen repetidamente usada por Francisco de la Iglesia como un hospital de campaña que debe salir al encuentro de los fieles heridos, podría imaginarse que, mientras esa tarea se realiza a través de la iniciativa pastoral propuesta en las primeras Reglas de procedimiento de Mitis Iudex, el tribunal eclesiástico será la "terapia intensiva" de dicho hospital, en la que se tratarán, con servicios especializados, a los que consideran "herido de muerte" su vínculo matrimonial, preguntándose por su validez o nulidad»: A. W. Bunge, Presentación del nuevo proceso matrimonial, en http://www.awbunge.com.ar/OtrosCursos.html, 6. En línea con el ejemplo, nos parece que la solución no se debe quedar simplemente en «aumentar» las camas en el hospital en la «terapia intensiva», sino en descubrir la raíz de la epidemia y atajarla: en este ejemplo médico, ésta sería la solución radical y definitiva; las demás soluciones son simplemente transitorias y de escasa eficacia.

${ }^{14}$ Ello requiere una reflexión por parte de los Pastores en la formación de los fieles sobre la concepción afectiva-sentimental del amor y la fidelidad. Pueden verse unas reflexiones en J. PeÑA VIAL, Fidelidad y amor conyugal a la luz de la Constitución Gaudium et Spes, Scripta Theologica 48 (2016) 79-92. 
Como es lógico, al tratarse de unas normas que regulan las causas matrimoniales, las Reglas se centran en algunos aspectos jurídicos y más próximos al proceso matrimonial, dando una serie de indicaciones a tener en cuenta por los Obispos. En el artículo comentaremos estos aspectos jurídicos al hilo de la investigación prejudicial con vistas al inicio de una causa matrimonial, dejando al lado otras muchas acciones o planteamientos pastorales que deben darse contemporáneamente en el tiempo, y no por ello menos importantes. La colocación de la ratio procedendi fuera del articulado del m.p. puede dar la sensación de que se trata de un aspecto secundario y marginal, pero nos parece que dadas las premisas y las intenciones de la reforma esta investigación tiene un puesto relevante ${ }^{15}$.

Por último, queremos señalar que esta normativa relativa a la investigación prejudicial se aplica indiferentemente a cualquier modalidad procedimental que posteriormente se plantee: proceso ordinario, brevior o documental.

\section{SuPUESTOS QUE PUEDEN ILUMINAR LA NATURALEZA DE LA INVESTIGACIÓN PREJUDICIAL}

En el actual ordenamiento canónico existen otras instituciones dentro del ámbito matrimonial que complementan a las nuevas disposiciones del m.p. Nos referimos a la investigación previa al matrimonio (cc. 1066-1072) y al examen de la demanda para su admisión que debe realizar el juez (art. 120 DC). Seguidamente nos referiremos al precedente legislativo de esta institución (art. 113 DC). Por último, junto a estas instituciones, nos queremos referir a la investigación previa penal, que puede iluminar algunos de los aspectos a tener en cuenta en este tipo de averiguaciones, en los que está en juego el bien público de la Iglesia y además hay que salvaguardar los derechos de los fieles.

\subsection{Investigación previa al matrimonio: $c c$. 1066-1072}

La normativa relativa a las medidas preparatorias a la celebración del matrimonio (investigación del estado de libertad de los contrayentes y publicaciones matrimoniales o proclamas) se recoge en los cc. 1066-1072 ${ }^{16}$, al regu-

${ }^{15}$ Conviene precisar que esta labor de consejo no cierra la posibilidad de introducir la causa directamente sin pasar por ella.

${ }^{16}$ Cfr. T. Rincón-PÉREZ, sub cc. 1066-1068, en Comentario exegético al Código de Derecho Canónico, III/2, Eunsa, Pamplona ${ }^{3} 2002,1121-1124$. 
lar el expediente matrimonial. El c. 1066 contiene un principio general y doctrinal dirigido a salvaguardar la válida y lícita celebración del matrimonio, al establecer «antes de que se celebre el matrimonio, debe constar que nada se opone a su celebración válida y lícita». El responsable de realizar dicho expediente es el párroco que de hecho va a asistir al matrimonio. Pero cabe la posibilidad de que lo realice otra persona, en cuyo caso sobre esta persona recae la obligación de comunicar el resultado de la investigación al párroco responsable mediante documento auténtico (c. 1070). Esta investigación es obligatoria, excepto en el caso de peligro de muerte: en esta situación es suficiente (si no se pueden conseguir otras pruebas, y si no hay indicios claros de lo contrario) la declaración de los contrayentes de que están bautizados y libres de todo impedimento.

La concreción del expediente matrimonial se ha dejado a cargo de cada Conferencia Episcopal, la cual deberá dar normas sobre: 1) el examen de los contrayentes, estableciendo el modo, extensión y contenido de este examen, que deberá coincidir con lo señalado en el Código para la válida y lícita celebración del matrimonio; 2) las proclamas matrimoniales u otros medios oportunos para realizar las investigaciones prematrimoniales.

Para los matrimonios que se celebran en España, la Conferencia Episcopal Española en el art. 12 del decreto de 26-XI-1983 ${ }^{17}$ establece: «para dar cumplimiento al c. 1067, hágase un expediente matrimonial que incluya el examen de los contrayentes y de los testigos indicados en el anexo de este Decreto». El anexo 2 al que se refiere la norma, contiene un esquema del modelo del expediente matrimonial. Entre los elementos que lo integran figuran los datos personales de los contrayentes; posibles impedimentos canónicos; consentimiento matrimonial; constatación de una formación suficiente prematrimonial, bien en cursos pastorales o bien en atención personal; dispensas y licencias; proclamas matrimoniales. En este modelo de expediente matrimonial no se hace referencia alguna a la fe de los contrayentes, tan sólo cuando se trata del examen de los testigos, se solicita a éstos que respondan sobre la existencia de alguno de los supuestos contemplados en el c. 1071 y si los contrayentes son personas creyentes o totalmente alejadas de la Iglesia.

Sobre los testigos recae la obligación que tienen los fieles de colaborar con el párroco para conseguir la válida y lícita celebración del matrimonio. A

${ }^{17}$ Cfr. Decreto General de la Conferencia Episcopal Española de 25-XI-1983, Boletín Oficial de la Conferencia Episcopal Española 3 (1984) 95-113. 
la hora de cumplir con este deber, convendrá tener en cuenta el precepto natural de no lesionar ilegítimamente la buena fama de que alguien goza, ni violar el derecho de cada persona a proteger su propia intimidad (c. 220). El examen de los testigos se basa en sus conocimientos personales de los novios: desde cuándo conocen al contrayente y la relación que han tenido con él; posibles impedimentos que conozcan y que afecten a los que se van a casar, preguntas sobre la existencia de algún supuesto del c. 1071, si consideran que el contrayente ha alcanzado la madurez suficiente y será capaz de cumplir las obligaciones del matrimonio o si le afecta alguna cualidad que pueda perturbar la vida conyugal.

Una buena preparación al matrimonio y la correcta realización del expediente matrimonial son claves para el futuro matrimonio: puede ayudar a solventar muchas de las dificultades en la futura vida conyugal o sortear posibles fracasos matrimoniales, así como evitar posibles nulidades matrimoniales por el planteamiento antropológico y vital que muestran los futuros contrayentes.

\subsection{Inquisición previa a la admisión de la demanda: art. 120 Instrucción Dignitas Connubii}

Esta investigación se desarrolla en un ámbito en el que las partes ya han introducido la demanda de nulidad ante el tribunal y el juez debe examinar si la acepta o no. Para asegurar que la demanda es apta para su admisión, el art. 120 DC admite dos supuestos en los que se puede dar cierta inquisición previa ${ }^{18}$ para las causas de nulidad matrimonial: $\ll$ $\$$ el presidente puede y debe, cuando el caso lo requiera, disponer que haya una investigación previa sobre la competencia del tribunal y la capacidad legal del actor para actuar en juicio. $₫ 2$ En cambio sólo puede disponer una investigación previa sobre la sustancia de la causa en orden a admitir la demanda o rechazarla, si ésta parece carecer de todo fundamento, e incluso solamente para valorar si cabe la posibilidad de que durante el proceso aparezca algún fundamento».

${ }^{18}$ Esta práctica era recomendada a veces, aunque no existía ninguna norma codicial ni postcodicial que la regulara, para evitar el escándalo que podría seguirse de la aceptación de demandas poco fundadas. La praxis consistía en un mini proceso, con interrogación extrajudicial de las partes, de los testigos más importantes, presentación de documentos, informaciones acerca de la credibilidad de unos y otros, etc. Un estudio histórico de la misma puede verse en R. RoDRíGUEZOCAÑA, La demanda judicial canónica, Pamplona 2002, 190-195. 
Esta investigación tiene lugar en una fase en la que la instancia judicial todavía no está plenamente instaurada ${ }^{19}$. Es cierto que con la introducción del libelo se da impulso y constituye el acto inicial, pero todavía no se ha instituido la relación trilateral entre el juez y las partes y las partes entre sí, que como indica el art. $129 \mathrm{DC}^{20}$, sólo cuando la parte demandada se ha presentado al juez inicia la instancia. De aquí se deduce que la investigación se debe hacer de modo sumario, sin la adopción de las formas propiamente procesales, y en la que puede ser llamado el actor para que clarifique algún punto, pero nunca al demandado (al no estar instituida la relación jurídica).

De esta verificación de los presupuestos procesales del libelo, el juez puede dar una decisión de rechazo solamente si (art. $121 \$ 1 \mathrm{DC}$ ): el tribunal es incompetente; la petición ha sido presentada indudablemente por alguien que no tiene derecho a impugnar el matrimonio; si el escrito de demanda no se ha redactado convenientemente (art. $116 \$ 1$, nn. 1-4 DC).

En relación al mérito de la causa, el libelo puede ser rechazado «si del mismo escrito de demanda se deduce con certeza que la petición carece de todo fundamento». Para ello la DC aclara en su art. 122 que «no hay fundamento para la admisión de la demanda si el hecho en que se basa la impugnación, aun siendo del todo verdadero, carece absolutamente de virtualidad para hacer nulo el matrimonio; o si, por más que el hecho sea de aquellos que hacen nulo el matrimonio, es manifiesta la falsedad de lo que se afirma». Se trata de una norma delicada: a primera vista parece contradecir el principio de que el actor tiene el derecho de que el fundamento o no de su petición se examine y se decida en un proceso, una vez que se han comprobado que reúne los presupuestos procesales para ello. En estos casos, la demanda viene rechazada tras un examen preliminar, con un decreto sumariamente motivado. Por esto, en los casos en que se decida el rechazo de la demanda sólo puede ser por las razones previstas en la ley, que son excepcionales y rígidas: se puede decir que se tratan de casos tan claros que, en realidad, su rechazo más que estar fundado en el mérito de la

19 «Tampoco en este caso se debe confundir la investigación preliminar del juez con la realizada por el servicio prejudicial, pero - una vez más- la finalidad que se persigue es la misma: evitar la tramitación de un proceso inútil por falta de fundamento en su petición»: P. A. MORENO GARCÍA, El servicio de indagación prejudicial: aspectos jurídico-pastorales, Ius Canonicum 56 (2016) 71.

20 «Una vez que haya sido notificada legítimamente la citación a la parte demandada, o ésta haya comparecido ante el juez para tratar de la causa, la instancia comienza a estar pendiente, y se hace propia del tribunal ante el cual se ha entablado la acción, con tal que sea competente (cfr. c. 1512, nn. 2-3, 5)»: art. 129 DC. 
causa se resuelve en un caso de legitimidad jurídica ${ }^{21}$. En ambos supuestos del art. 120 DC, el juez que rechaza la demanda debe hacerlo mediante decreto: éste puede ser recurrido por la parte a tenor del art. 124 DC.

Por tanto, no se trata de indagar acerca del mérito de la causa, ni de anticipar el juicio del tribunal, sino de comprobar que cumple los requisitos señalados por el legislador para iniciar un proceso ${ }^{22}$ : sus límites son más bien estrechos, lo que supone que esta inquisición previa no puede convertirse en un proceso antes del proceso.

Ante la posible pregunta de si esta institución quedaría en desuso dada la nueva normativa, conviene tener en cuenta el c. $1676 \$ 1$ : antes de admitir la demanda y de citar al defensor del vínculo y a la otra parte, se sigue disponiendo esta comprobación del fundamento del libelo, ahora por el Vicario Judicial. Por esto, nuestra opinión es que sigue vigente y será necesaria su puesta en marcha, sin excluir los supuestos de las demandas que hayan pasado por la nueva investigación pastoral ${ }^{23}$.

\subsection{Precedente: la estructura consultiva diocesana del art. 113 Instrucción Dignitas Connubii}

La investigación previa prevista en las nuevas RP tiene su antecedente en lo dispuesto en el art. $113 \$ 1 \mathrm{DC}$ : «en cada tribunal debe haber un servicio o una persona a los que pueda dirigirse cualquiera, con libertad y fácilmente, para aconsejarse sobre la posibilidad de introducir la causa de nulidad de su matrimonio y sobre el modo de proceder, en la medida en que pudiera haber fundamento» ${ }^{24}$.

La norma introducía una oficina o ministro del tribunal para aconsejar en las causas de nulidad matrimonial. La creación de este órgano no era facultativa sino obligatoria, teniendo en cuenta evidentemente las posibilidades del

${ }^{21}$ Cfr. G. Maragnoli, sub art. 122 DC, en M. Del Pozzo - J. Llobell - J. MiÑambres (eds.), Norme procedurali canoniche commentate, Coletti a San Pietro, Roma 2013, 384-385.

22 Cfr. R. Rodríguez-OcaÑa, «Admisión a la demanda», en J. OtaduY - A. Viana - J. SEDANO (eds.), Diccionario General de Derecho Canónico, vol. I, Aranzadi, Pamplona 2012, 250-252 (en adelante, $D G D C$ ).

${ }^{23}$ Como se estudiará más adelante, la demanda interpuesta tras la realización de la investigación previa teóricamente no es garantía de que se cumplan todos estos requisitos procesales.

${ }^{24}$ Algunos comentarios a esta norma pueden verse en J. GARCía MONTAGUd, El nuevo servicio de orientación jurídica de los Tribunales Eclesiásticos, en J. OTADUY (ed.), Nuevas situaciones, nuevas leyes, nuevas respuestas (Actas de las XXIX Fornadas de Actualidad Canónica organizadas por la Asociación Española de Canonistas en Madrid, 15-17 de abril de 2009), Dykinson, Madrid 2010, 161-189; J. M. Díaz Moreno, Anotaciones personales sobre el «servicio de orientación jurídica», ibid., 191-207. 
tribunal. El cónyuge podía acudir libremente al «consultorio matrimonial». No se trataba de un juicio previo o sumario sino de un consejo solícito y ecuánime sobre los extremos y la modalidad de la posible acción.

Para llevar a cabo esta labor, en el tercer parágrafo del art. 113 DC se recomendaba vivamente que, en la medida de lo posible, se establecieran patronos estables, retribuidos por el propio tribunal, que pudieran desarrollar la función de consejo del parágrafo primero y además, pudieran ser escogidos como abogados o procuradores en las futuras causas matrimoniales que se pudieran entablar. En todo caso, la norma no indicaba requisitos especiales en las personas que podían desarrollar esta labor consultiva, por lo que se debía entender en sentido amplio: no era necesario ni títulos especiales, ni el sacerdocio, aunque lógicamente era necesaria una adecuada preparación técnica, pastoral y humana ${ }^{25}$.

Además, en el parágrafo 2 se introducía un régimen de incompatibilidad que protegía la autenticidad e imparcialidad del futuro proceso: el rol de asistencia ya realizado prohibía el ejercicio de la función de juez y defensor de vínculo en el futuro proceso de nulidad sobre ese matrimonio, pero no para ejercer como notario o como patrono de las partes.

Como se ve, la labor de asesoramiento llevada a cabo primariamente tenía por finalidad informar de las posibilidades de actuación, y sólo posteriormente, si la parte lo veía oportuno y con la intervención de un abogado (que podía ser el patrono estable que le había asesorado previamente), se debía realizar toda la labor jurídica necesaria con el fin de la presentación de la demanda ante el juez ${ }^{26}$. Indudablemente, lo que parece claro es que estas indicaciones vienen integradas en el nuevo servicio de ayuda predispuesto en las actuales RP.

\subsection{Investigación previa al juicio penal: cc. 1717-171927}

$\mathrm{Al}$ tener noticia de la comisión de un delito (c. $1717 \$ 1$ ), corresponde al Ordinario tomar la decisión mediante decreto de iniciar o no la investigación, que tiene como fin obtener la información oportuna sobre la verdad de los he-

${ }^{25}$ Cfr. M. Del Pozzo, sub art. 113 DC, en M. del Pozzo - J. Llobell - J. Miñambres (eds.), Norme procedurali canoniche commentate, Coletti a San Pietro, Roma 2013, 374-375.

${ }^{26}$ Este precedente tuvo poca aplicación: se consideraba que estaba escasamente definido técnicamente (se trataba de una recomendación que solía ser llevada a cabo por los patronos estables) y por tener un fin y alcance más bien limitado: cfr. M. DEL POZZO, Il processo matrimoniale più breve davanti al Vescovo, Edusc, Roma 2016, 90.

27 Cfr. J. SANCHIS, sub cc. 1717-1719, en Comentario exegético al Código de Derecho Canónico, IV/2, Eunsa, Pamplona ${ }^{32002,2062-2074 . ~}$ 
chos cometidos y sobre su autor, es decir, determinar si la noticia sobre la comisión del delito tiene o no fundamento, y a partir de tales datos poder decidir sobre las medidas a adoptar. Aunque el propio Ordinario podría realizar personalmente la investigación, se le aconseja que la encomiende a otra persona. El investigador realiza su trabajo bajo la dirección del Ordinario, el cual le podrá dar las instrucciones oportunas.

Todas las actuaciones realizadas por el investigador deberán observar las formalidades establecidas por el derecho, recogiéndolas por escrito con la intervención del notario, a fin de obtener una fiel documentación de los actos realizados. Por la peculiaridad de la investigación, el investigador «tiene los mismos poderes e idénticas obligaciones que el auditor en un proceso». A tenor del c. $1428 \$ 3$, al investigador corresponde recoger las pruebas, decidiendo «qué pruebas han de recogerse y de qué manera». A la realización de la investigación se aplican, por tanto, con las oportunas adaptaciones, las normas contenidas en los cc. 1526-1583 sobre las pruebas.

Esta investigación que regula el Código no es una fase del proceso penal, sino un instituto jurídico autónomo de naturaleza administrativa, previa o preliminar al procedimiento penal propiamente dicho, y común a las dos vías que posteriormente podrá adoptar: judicial o administrativa. De lo que se deduce que las actas de la investigación tienen también naturaleza administrativa, con todas las consecuencias jurídicas que de ello se deriva. Por tal motivo, las pruebas recogidas en las actas o sumario de la investigación no son tales en sentido judicial propio y verdadero: para que tengan valor y fuerza probatoria, y sirvan en orden a la sentencia, deberán ser alegadas de nuevo en el juicio.

En el desarrollo de la investigación se ha de evitar que se ponga en peligro innecesariamente la buena fama del investigado (c. $1717 \$ 2$ ), además de guardar la debida discreción o reserva, por motivo de la gravedad de la causa.

El oficio de investigador debe ser desempeñado por una persona idónea, clérigo o laico, hombre o mujer. En todo caso, para garantizar la objetividad y la imparcialidad, quien desempeñe el oficio de investigador, «si se realiza después un proceso judicial, no puede desempeñar en él la función de juez» (c. $1717 \$ 3)$.

Al final de la investigación, el Ordinario deberá decidir, mediante decreto, la conclusión de la investigación (c. $1718 \$ 1$ ), teniendo presente el parecer del investigador, cuando estime que ya «se han reunido los elementos suficientes» para tener una idea lo más exacta posible de los hechos. Las cuestiones que deben ser objeto de valoración prudencial por parte del Ordinario 
son: la posibilidad del proceso, su oportunidad, y si se debe seguir la vía administrativa o la judicial.

La responsabilidad de la investigación preliminar recae totalmente sobre el Ordinario: inicio, conclusión y decisiones. Como veremos más adelante es muy diferente la normativa de la investigación prejudicial o pastoral matrimonial, por lo que toda referencia hacia la investigación penal deberá ser por analogía y realizada con mucha prudencia.

\section{Premisas en el nuevo servicio de investigación Prejudicial}

En este apartado trataremos algunos aspectos esenciales del nuevo servicio de investigación prejudicial.

\subsection{Necesidad de constituir el servicio pastoral en la diócesis y su posible obligatoriedad como requisito a la demanda de nulidad}

Teniendo en cuenta las expresiones de la Norma (arts. 2 y 3 RP), la primera valoración de la doctrina era que este servicio se presentaba como algo deseable de poner en marcha en cada diócesis (incluso dentro de la diócesis, a nivel parroquial), aunque no parecía estrictamente obligatorio ${ }^{28}$. Sin embargo, posteriormente, en el Subsidio aplicativo enviado por la Rota Romana, se indica que «el primer paso que los Obispos están llamados a realizar es la creación de un servicio de información, de asesoría y de mediación vinculado con la pastoral familiar, que podrá acoger a las personas con ocasión de la investigación preliminar al proceso matrimonial $\gg^{29}$. El Subsidio relaciona esta afirmación con la Relatio finalis del Sínodo de los Obispos: «será por lo tanto necesario poner a disposición de las personas separadas o de las parejas en crisis, un servicio de información, de asesoría y de mediación, vinculado con la pastoral familiar, que podrá también acoger a las personas con ocasión de la investigación preliminar al proceso matrimonial (cfr. MI, arts. 2-3) (Sínodo, $R e-$ latio finalis, $\left.\mathrm{n}^{\mathbf{0}} 82\right) \gg^{30}$. De estos dos textos del Subsido se puede colegir que existe una clara voluntad por parte del Legislador de que en cada diócesis se

${ }^{28}$ Cfr. G. BonI, La recente riforma del processo di nullità matrimoniale. Problemi, criticità, dubbi (parte terza: $\int S 5$ 5-7), Stato, Chiese e pluralismo confessionale. Rivista telematica (http://www.statoechiese.it/ 21 marzo 2016), 11/2016, 57.

29 Tribunal apostólico de la Rota Romana, Subsidio, 13.

${ }^{30}$ Ibid., 14. 
implemente una estructura, más o menos articulada y compleja, que pueda realizar esta labor tanto en su nivel más pastoral y de mediación, como en su labor informativa y de asesoramiento técnico jurídico con vistas a una posible instauración del proceso matrimonial ${ }^{31}$.

Otra de las dudas que ha suscitado la normativa proviene de la formulación del art. 4 RP, y hace referencia a si las partes tienen la obligación de acudir a la investigación prejudicial como requisito previo a la introducción de un proceso $^{32}$; es decir, si constituiría un requisito sine qua non para acceder a los tribunales eclesiásticos. La respuesta que ha dado la doctrina es que es un servicio facultativo para los fieles ${ }^{33}$. Esta conclusión viene reforzada por lo dispuesto en el art. $5 \mathrm{RP}$ que afirma que la investigación se cierra, si es el caso, con la presentación del libelo ante el tribunal competente ${ }^{34}$.

\subsection{Acompañamiento pastoral que debe darse en todo momento a los contrayentes}

En este apartado nos queremos preguntar por el fin al que debe tender esta investigatio. Este fin está enmarcado en el art. 2 RP: «la investigación prejudicial o pastoral, que acoge en las estructuras parroquiales o diocesanas a los fieles separados o divorciados que dudan de la validez de su matrimonio o están convencidos de la nulidad del mismo, se orienta a conocer su condición y a recoger elementos útiles para la posible celebración del proceso judicial, ordinario o más breve». Como afirma la norma, esta investigación mira a acoger y prestar específica atención a los fieles en dificultad. El fin, por tanto, no es la preparación inmediata y directa del proceso sino el discernimiento acerca de la posible validez del matrimonio. Nos parece impropio y reductivo presentar la investigatio como la recogida de datos e indicios en vista a la futura demanda. En primer lugar, es necesario hacer luz y ayudar a entender y, probablemente, elaborar lo vivido en el matrimonio ${ }^{35}$. En esta clave se debe entender también el sucesivo art. 4 RP

31 Tiene su importancia por el nombramiento de los consejeros que deberán hacerla y su influencia en el organigrama judicial del tribunal diocesano.

${ }_{32}$ Cfr. G. BONI, La recente riforma..., cit., parte terza, 57.

33 Cfr. P. A. Moreno García, El servicio de indagación..., cit., 71-72.

34 También refuerza a esta conclusión la posibilidad de la presentación de la demanda oral del art. 10 RP: en esta hipótesis seguramente habrá supuestos de presentación de demandas de nulidad en que las partes no han sido asesoradas previamente.

35 «Senza una seria e serena rielaborazione del proprio vissuto alla luce della fede ed una conseguente maturazione umana e cristiana, un'eventuale nullità matrimoniale non arrecherebbe un 
«la investigación pastoral recoge los elementos útiles para la eventual introducción de la causa por parte de los cónyuges o de su representante ante el tribunal competente. Se investigue si las partes están de acuerdo al pedir la nulidad». No cabe duda que, tras la acogida y el acompañamiento, se puede llegar a la conclusión de aconsejar la introducción de la demanda ${ }^{36}$. Esta investigatio consiente establecer y definir los términos del debate, pero concebir la consulta pastoral como un expediente en sentido único y a un fin predeterminado es en definitiva erróneo y deformante ${ }^{37}$.

Por otra parte, el c. 1675 pone como premisa de toda instancia el fracaso de la unión matrimonial al disponer que «el juez, antes de aceptar la causa, debe tener la certeza de que el matrimonio haya irreparablemente fracasado, de modo que sea imposible restablecer la convivencia conyugal ${ }^{38}$. Esta norma replantea la importancia de que se realice bien la investigación prejudicial: ésta no debe limitarse a comprobar la existencia de la ruptura y separación, sino más bien a encontrar las causas de la unión conyugal fallida ${ }^{39}$. En las crisis familiares es sabido que el cálculo y el interés quitan serenidad y transparencia en la visión y decisiones que adoptan los cónyuges, y sería útil intentar anticiparse a ello antes de que soliciten la nulidad de su matrimonio. La iniciativa y solicitud de los agentes de pastoral, especialmente de los párrocos, tiene una importancia capital en este sentido: una actitud de simple recibimiento de las aspiraciones de los cónyuges, ya constituiría una forma de resignación y manifestación de que no se puede hacer nada ${ }^{40}$, actitud que pensamos no sería respetuosa con el espíritu de la reforma.

En cuanto al espíritu con el que los agentes de pastoral deben afrontar las crisis matrimoniales conviene resaltar las palabras del Subsidio: «este camino de "acompañamiento" puede ayudar a superar las crisis matrimoniales de manera satisfactoria, pero también está llamado a verificar, en los casos concretos, la ver-

vantaggio significativo per la vita di questi fedeli»: E. ZANETTI, La consulenza previa all'introduzione di una causa di nullità matrimoniale, en La Riforma dei processi matrimoniali di papa Francesco. Una guida per tutti, Quaderni di diritto ecclesiale, Ancora Editrice, Milano 2016, 10-11.

${ }^{36}$ Cuando el art. $5 \mathrm{RP}$ indica que «recogidos todos los elementos, la investigación se cierra con el libelo, para presentar, si es el caso, en el tribunal competente» hay que enmarcarlo en un articulado de una norma procesal.

37 Cfr. M. DEL Pozzo, Il processo matrimoniale..., cit., 154.

38 Similar disposición se indica en Tribunal Apostólico de la Rota Romana, Subsidio, 23.

39 Indudablemente no se puede pensar que la Iglesia pueda llegar siempre, o muy frecuentemente, a solucionar estos problemas conyugales, pero al menos debería intentarlo con medios respetuosos.

40 Cfr. M. DEL Pozzo, Il processo matrimoniale..., cit., 154. 
dad de la validez o no del matrimonio y "a recoger elementos útiles para la eventual celebración del proceso judicial, ordinario o más breve" $\gg^{41}$. La garantía de la fructuositas y respuesta de este medio pastoral, que la Iglesia desea que siempre se implemente, reside sobre todo en la corrección y exactitud de la forma mentis y de la inclinación de los agentes de pastoral, que no deben dejarse llevar por una mala concepción de pastoralismo que contrapone justicia y pastoralidad ${ }^{42}$. La atención de matrimonios fracasados requiere mucha atención y cautela por parte de los pastores: no pueden caer en el peligro de claudicar ante las situaciones de rupturas matrimoniales, y mucho menos en aconsejar con demasiada ligereza «intentar» el camino del proceso canónico. Si no hay una presunción al menos subjetiva de la nulidad del propio matrimonio, o un motivo suficiente para dudar de la validez del matrimonio, es inútil enviar a los esposos a la justicia eclesiástica ${ }^{43}$. El pastor, el consultor, el fiel no son jueces, no pueden concebir el proceso judicial como un medio rápido y eficaz para resolver una situación pastoral delicada, por esto los consultores pastorales (párrocos, patronos estables, catequistas, etc.) deben actuar con cautela y prudencia ${ }^{44}$.

Aquí deseamos hacer un apunte sobre el acompañamiento y atención de la autoridad en esas situaciones de fracaso matrimonial: en las crisis matrimoniales es decisiva la prontitud de la actuación para intentar solventarlas, ya que una intervención tardía de la autoridad en el acompañamiento a los esposos la haría posiblemente ineficaz. Una dificultad manifestada y sopesada in Ecclesiae tendrá mucha más posibilidades de ser superada o reconducida correctamente. Como la pastoral más eficaz es la que previene y protege, nos parece que el acompañamiento de los cónyuges debería corresponder a una acción duradera y constante ante los contrastes o rupturas en los matrimonios de los fieles.

En resumen, como se ha visto, la normativa orienta esta estructura consultiva en referencia al posible proceso posterior, pero la instauración de la causa judicial es una posibilidad (no la única, ni siquiera la deseable) de todo el trabajo en esta fase: en este supuesto, nunca deberá concebirse como una fi-

41 Tribunal Apostólico de la Rota Romana, Subsidio, 14. Por tanto, la vía del proceso de nulidad representa una salida eventual y extrema.

42 Cfr. San Juan Pablo II, Discurso a la Rota Romana, 18-I-1990, n. 4, AAS 82 (1990) 874.

43 Cfr. C. J. ERrázuriz M., Licitud moral de la presentación de la demanda de nulidad matrimonial por los esposos, Ius Canonicum 41 (2001) 169-189.

${ }^{44}$ Cfr. M. DEL Pozzo, Il processo matrimoniale..., cit., 154-155. 
nalidad del resultado del apoyo y ayuda que se presta ${ }^{45}$. La misma expresión de investigación que connota indagación, examen, búsqueda sería mejor presentarla con la dicción «acompañamiento y acogida», utilizada en el Sínodo ${ }^{46}$. Este servicio puede y debe ser mucho más amplio y articulado de la simple (y en muchos casos elemental) competencia jurídico-canónica. La investigación, a fin de cuentas, constituye un aspecto de un empeño más profundo y global que, como indica el art. 2 RP, se desarrollará en el ámbito de la pastoral matrimonial diocesana unitaria.

\subsection{A quién va dirigido este servicio pastoral}

Algunos autores han manifestado su «sorpresa» por la circunstancia de que la nueva regulación se «centre» de una manera acusada en los matrimonios ya fallidos, sin mencionar la labor pastoral que se debe realizar con todas las familias con el fin de que no se lleguen a esas otras situaciones extremas ${ }^{47}$. Esta opinión se basa, primero, en las expresiones que utiliza la reforma en el c. 1675 , el art. 1 RP y el Subsidio cuando se refieren a la labor pastoral del Obispo y sacerdotes, que debe dirigirse hacia los matrimonios fracasados, cónyuges separados o divorciados que hayan abandonado la práctica religiosa; $y$, segundo, en la insistencia casi exclusiva, por parte de algunos de los redactores en la solicitud pastoral hacia esos fieles en dificultad ${ }^{48}$, subrayando la misión del Obispo que, «como el buen Pastor», está obligado a ir al encuentro de estos fieles que tienen necesidad de un especial cuidado pastoral (lo que sería cierto, sin olvidar que su solicitud pastoral debe dirigirse a todos $\left.{ }^{49}\right)$.

Se nos permita hacer alguna reflexión en relación a la expresión de matrimonio fracasado que utiliza el c. 1675: esta locución se refiere al matrimo-

${ }^{45}$ No es baladí que el art. 5 de las Reglas contiene el inciso «si es el caso» en referencia a la presentación de la demanda judicial.

${ }^{46}$ Cfr. XIV Asamblea General Ordinaria del Sínodo de los Obispos, 2015, Relación final, nn. 77-83.

${ }^{47}$ Cfr. G. BonI, La recente riforma..., cit., parte terza, 21-27.

${ }^{48}$ Cfr. A. W. Bunge, Presentación..., cit., 7-8.

49 «Pero, mientras que nos ocupamos de las heridas de quienes piden la verificación de la verdad sobre su matrimonio que ha fracasado, miramos con admiración a quienes, incluso en condiciones difíciles, permanecen fieles al vínculo sacramental. Estos testigos de la fidelidad matrimonial deben ser alentados y señalados como ejemplos a imitar. Muchas mujeres y muchos hombres soportan situaciones pesadas, de gran peso, para no destruir la familia, para ser fieles en la salud y en la enfermedad, en las dificultades y en la vida serena: es la fidelidad. ¡Es buena gente!»: FRANCISCO, Discurso pronunciado en la audiencia a los participantes al Curso de formación promovido por el Tribunal de la Rota Romana, 12 marzo 2016, en http://w2.vatican.va/content/francesco/es/speeches/2016/march/documents/papa-francesco_20160312_corso-rota-romana.html. 
nio in facto esse como un elemento necesario previo para iniciar el proceso de nulidad. Como es sabido, el juez debe mirar a la nulidad del matrimonio y no a una condición extrínseca del mismo: si un matrimonio es inválido lo es aunque los cónyuges estén conviviendo pacíficamente. Un matrimonio fracasado no es un matrimonio nulo: la nueva normativa del proceso de nulidad no se puede concebir como un remedio para aquellas situaciones matrimoniales «colapsadas» después de la celebración del matrimonio ${ }^{50}$, o incluso inducir a los fieles a olvidar la indisolubilidad de su unión; y lo que sería más grave, podría suscitar en los fieles la idea de que, la posible intervención de la institución eclesiástica en las causas de nulidad es la de mera constatación de un fracaso $^{51}$, cosa que nunca debería suceder.

\subsection{Necesidad de una mediación en la fase prejudicial}

Desde el mismo momento de la publicación del m.p. surgieron voces críticas $^{52}$ al no existir en ella alguna directriz pastoral sobre mediación o búsqueda de la reconciliación matrimonial que en todo momento la Iglesia, como Madre, debe perseguir. Aunque en el c. 1675 reformado puede intuirse una referencia a la labor del juez en esta materia ${ }^{53}$, en las RP no se hace alguna indicación explícita a esta labor, cosa que, a primera vista, resultaría lo más adecuado y conveniente: en lo pastoral, lo primero debe ser la reconciliación y el perdón de los esposos entre sí, siempre que sea viable. Es decir, no dar de antemano como imposible reconducir la situación. Aunque también es cierto que muchos de los supuestos en que esta pastoral se moverá no serán en los momentos previos a la ruptura matrimonial, o inmediatamente posteriores, en los que la ayuda podría ser eficaz para recomponer la situación.

Estas críticas también provenían de la comparación del c. 1676 de la anterior legislación con las nuevas normas. Llamaba la atención que en una nor-

${ }^{50}$ Cfr. G. BonI, La recente riforma..., cit., parte terza, 25-26.

${ }^{51}$ Un análisis doctrinal sobre la actitud pastoral de la autoridad eclesiástica sobre los divorciados «víctimas» de la infidelidad del otro cónyuge, que tratan de vivir su situación de acuerdo con la doctrina de la Iglesia, y los divorciados vueltos a casar, puede verse J. LLOBELL, Los procesos matrimoniales en la Iglesia, Rialp, Madrid 2014, 56-75.

52 Alguna doctrina se ha llegado a plantear si la reconciliación es una palabra y una prospectiva completamente olvidada en el m.p., en la investigación prejudicial o pastoral (cfr. G. BONI, La recente riforma..., cit., parte terza, 23-24). Parece que las menciones que se hacen en el Subsidio a la mediación en la fase prejudicial y en la fase de aceptación de la demanda son debidas a estas críticas.

${ }^{53}$ Cfr. A. W. Bunge, Presentación..., cit., 14. 
mativa que se desea que esté imbuida de pastoral no se mencionen los remedios pastorales tradicionales en el ámbito matrimonial: la mediación y la posible sanación de matrimonios nulos. El nuevo c. 1675 señala que «el juez, antes de aceptar la causa, debe tener la certeza de que el matrimonio haya irreparablemente fracasado, de modo que sea imposible restablecer la convivencia conyugal», no menciona el remedio pastoral de la mediación que el canon paralelo derogado contenía, con el fin de conseguir -si se preveía algún éxito- la reconciliación de los cónyuges utilizando si era necesario la convalidación y sanación del matrimonio, que todo juez debe intentar ${ }^{54}$. Si el anterior canon respiraba algo de esperanza, ahora se habla de matrimonio irreparablemente fallido con una nota algo pesimista ${ }^{55}$, con el peligro de que todas las personas que se relacionan en estos temas (jueces, abogados, consejeros) lleguen a inhibirse de la responsabilidad sobre la reconciliación ${ }^{56}$. Por otra parte, en el apartado correspondiente a la aceptación de la demanda y con referencia al nuevo c. 1675 , en el Subsidio se dice « ¿es necesario realizar el tentativo de reconciliación? La experiencia dice que, cuando se llega a la causa de nulidad, es ya del todo imposible recomponer la convivencia. Por tanto, bastará que el juez, antes de aceptar la causa, posea la certeza de que el matrimonio ha fracasado irreparablemente y es imposible restablecer la convivencia conyugal ${ }^{57}$. Esta mentalidad puede estar muy difundida y, en mi opinión, no es exactamente correcta.

Quizás en reacción a estas críticas, el Subsidio otorga unas competencias más amplias a este munus en la fase prejudicial, incluyendo también una ade-

54 «Teniendo en cuenta el deber de proteger la institución matrimonial y los grandes bienes que entran en juego con ella, resulta absolutamente necesario que el primer objetivo de la fase preliminar, ya sea por parte del juez -de oficio- como a través del servicio de indagación prejudicial -a instancia de parte- sea tratar de restablecer la convivencia y, en su caso, procurar la convalidación del matrimonio»: P. A. MoReno GarCÍA, El servicio de indagación..., cit., 71.

55 Cfr. R. RodrígueZ-OcaÑa, Nueva regulación de los procesos de nulidad matrimonial, Scripta Theologica 48 (2016) 309.

56 O incluso sobre la verdad de la validez del matrimonio: cfr. G. BONI, La recente riforma..., cit., parte terza, 23.

57 Tribunal Apostólico de la Rota Romana, Subsidio, 23. En esta fase de la aceptación de la demanda, como indica algún autor, la prueba de la obtención de la separación legal y de la sentencia de divorcio sería suficiente (casi siempre) para comprobar el fracaso matrimonial y la imposibilidad de la reconciliación de las partes. Una eventual demanda conjunta de los cónyuges, o el consenso de la otra parte, reforzarían tal convencimiento de la no posible reconciliación matrimonial. En este contexto es oportuno tener presente las disposiciones del art. $65 \$ \$ 2$ y 3 DC: cfr. A. ZAMBON, La presentazione del libello, en La Riforma dei processi matrimoniali di papa Francesco. Una guida per tutti, Quaderni di diritto ecclesiale, Ancora Editrice, Milano 2016, 43-44. 
cuada mediación para aquellas parejas que necesitan esa ayuda orientada a superar las crisis de convivencia conyugal, al establecer tres líneas de actuación, siguiendo un orden lógico de sucesión en el tiempo: a) ayudar a superar las crisis conyugales; b) recoger los elementos útiles para las causas de nulidad matrimonial; c) elaborar el libelo de demanda a presentar ante el tribunal competente ${ }^{58}$.

\section{CAPACIDAD JURÍDICA E IDONEIDAD DEL AGENTE QUE REALIZA ESTE ASESORAMIENTO PASTORAL Y LA INVESTIGACIÓN}

Como ya hemos resaltado, el núcleo del nuevo proceso de nulidad matrimonial está en la llamada al acompañamiento pastoral de los cónyuges de esta fase prejudicial ${ }^{59}$. Así, nos indica el Subsidio al decir que «la efectiva aplicación del nuevo proceso para la declaración de la nulidad del matrimonio requiere no sólo de las estructuras estrictamente jurisdiccionales sino también del servicio pastoral que permita a los fieles acceder con su solicitud de declaración de la nulidad ya sea al Obispo como al tribunal más cercano» ${ }^{60}$.

Este servicio pastoral debe realizarse bajo el prisma de la comprensión humana y el acompañamiento espiritual de las personas que han conocido la ruptura del propio matrimonio, con el fin de hacer experimentar el calor de la maternidad de la Iglesia y evitar desagradables equívocos y malentendidos. Pero a su vez, quienes lo realizan deben tener la conciencia clara de que su rol es simplemente de consejo y de mediación, y que podrá ser de gran ayuda al trabajo de los jueces.

Según la normativa esta función de consejo puede venir a través de una duplicidad de formas o niveles de prestación de la ayuda requerida: 1) una persona; 2) una estructura estable diocesana. Los dos parágrafos del art. $3 \mathrm{RP}$ parecen delinear posibilidades o grados de actuación de este servicio, que pueden ser cumulativos o sucesivos, también en lo que se refiere a la cualificación y especialización de los mismos ${ }^{61}$.

${ }^{58}$ Cfr. Tribunal Apostólico de la Rota Romana, Subsidio, 16.

${ }^{59}$ Cfr. M. DEL Pozzo, L'organizzazione giudiziaria ecclesiastica alla luce del m. p. «Mitis iudex», Stato, Chiese e pluralismo confessionale. Rivista telematica (http://www.statoechiese.it/ 23 novembre 2015), 36/2015, 22.

60 Tribunal Apostólico de la Rota Romana, Subsidio, 13. Es interesante la experiencia de la archidiócesis de Milán sobre la estructura puesta en marcha: cfr. M. MosCONI, Il nuovo «Ufficio diocesano per l'accoglienza dei fedeli separati» dell'Arcidiocesi di Milano, Ius Ecclesiae 27 (2015) 716-730.

${ }^{61}$ Cfr. M. DEL Pozzo, L'organizzazione giudiziaria..., cit., 22. Parecidas consideraciones se pueden encontrar en E. ZANETTI, La consulenza previa..., cit., 18-22. 


\subsection{El encargo de la función de aconsejar y de acompañamiento pastoral}

La primera forma de prestación del auxilio y labor prejudicial la constituye el encargo funcional o personal. El art. $3 \mathrm{RP}$ señala un doble criterio en la elección del agente pastoral: el propio párroco o el que preparó a los cónyuges para la celebración de la boda son propuestos para esta labor, por así decir, señalado por el derecho en razón del oficio o de la función desarrollada. A estas personas, se pueden añadir otros clérigos, consagrados o laicos aprobados por el Ordinario del lugar. La referencia en primer lugar al párroco implica una segura garantía de acogida y sobre todo que se cumplirá la exigencia de una sensibilidad pastoral. Con este criterio, la intención de la norma es clara: pretender que, antes de que se inicie un proceso judicial, se instaure no sólo una serena investigación sino un momento de escucha y de discusión, en el conjunto de la pastoral familiar diocesana.

Indudablemente, esta actuación de los párrocos no excluye, más bien busca, soluciones posteriores más cualificadas: al lado pastoral se debe asociar una competencia o experiencia específicamente matrimonial en la misma persona del clérigo o de otros. Por esto, más que un consejero, sería mejor la intervención de varios consejeros, que podrán valorar la posibilidad de una mediación y reconciliación y dar la ayuda humana, cristiana y profesional necesaria para dirigir correctamente las diversas actuaciones y las necesidades que cada situación matrimonial requiera ${ }^{62}$.

En cuanto a las características de la figura, los elementos que se recaban del art. 3 RP son: a) una específica designación por parte del Ordinario del lugar; b) la competencia adecuada y c) la diversa condición canónica ${ }^{63}$.

El trabajo de consejo requiere una habilitación para intervenir en este ámbito prejudicial, que se retiene implícita o general en los párrocos y específica en otros sujetos. Se podría plantear si esta aprobación por parte del Ordinario del lugar tiene una finalidad restrictiva en relación a las personas que son aptas y que pueden prestar la ayuda. Al ser optativo y libre para el fiel este servicio, al que podrá acudir o no, nuestra opinión es que esta habi-

\footnotetext{
${ }^{62}$ La recogida de elementos útiles para el futuro proceso no sólo no es el objetivo exclusivo, sino que no debe deformar el sentido del mandato eclesial de acogida: interesa en primer lugar curar y recuperar a los fieles en dificultad.

${ }^{63}$ Cfr. M. DEL Pozzo, L'organizzazione giudiziaria..., cit., 23.
} 
litación sobre todo tiende a garantizar el buen consejo pastoral y jurídicocanónico ${ }^{64}$.

La competencia requerida que deben poseer estos agentes pastorales se precisa explícitamente que no es sola la canónica, sino que además puede estar basada en la propia ciencia y experiencia. Como ya hemos visto, el espíritu de la norma quiere ofrecer una atención humana más profunda y completa que de la sola pericia técnico-jurídica; es decir, que el encuentro y el acompañamiento deben ir más allá de la simple investigación de las posibles causas de nulidad. Dado el amplio campo de actuación, que puede ir desde el acompañamiento espiritual y humano, la mediación en las crisis del matrimonio, hasta llegar a un estudio sobre la posible nulidad del matrimonio, todo esto plantea la necesidad de personal cualificado, lo que supondrá un notable esfuerzo en el trabajo formativo, para que todos los agentes que intervienen en la fase prejudicial gocen de la idoneidad necesaria para ello ${ }^{65}$.

$\mathrm{Al}$ estar estos artículos en una normativa procesal, queremos hacer un pequeño excursus sobre la competencia jurídico canónica que debería poseer el investigador a la hora del asesoramiento. La pregunta que nos hacemos es: dada esta complejidad en las situaciones matrimoniales, que los motivos de nulidad son de carácter técnico jurídico, ¿no parecería más lógico que el asesoramiento jurídico lo realice un experto de derecho canónico? ${ }^{66}$ Que se haga bien o no esta labor podrá evitar expectativas de sentencias de declaración de nulidad: el juez se mueve en el terreno de la certeza moral jurídica, no en el de las impresiones, opiniones, apariencias e indicios, más o menos fundados ${ }^{67}$.

Hasta ahora la indicación que existía en la DC indicaba que debía de realizarse por una persona especializada en derecho (ya sea a través de la oficina diocesana o de los patrones estables, cfr. art. $121 \$ \$ 1$ y 3 DC). Hoy, con la nueva legislación la calidad del asesoramiento ha cambiado, ya que los sujetos

${ }^{64} \ll$ La richiesta approvazione comunque non intende fissare un principio limitativo o restrittivo nell'aiuto ma garantire l'affidabilità del supporto pastorale e del consiglio canonico»: M. DEL Pozzo, Il processo matrimoniale..., cit., 88, nt. 32.

65 Cfr. J. P. BEAL, «Mitis Iudex» Canons 1671-1682, 1688-1691: A Commentary, The Jurist 75 (2015) 526. P. A. Moreno GarCía, El servicio de indagación..., cit., 73.

${ }^{66}$ Cfr. J. Llobell, Los procesos matrimoniales..., cit., 148.

${ }^{67}$ Piénsese en supuestos en los que se presente la demanda sin completar los requisitos exigidos; o no presentar los documentos necesarios; o no adjuntar algún documento esencial para el inicio del proceso abreviado que, mostrando muchos elementos para iniciar el proceso y la posible nulidad, no responda totalmente a todas las cuestiones a dilucidar y el Vicario judicial vea necesario solicitar que se complete, originando además más gastos a la parte; etc. 
«reclutables»y designados por el Ordinario del lugar no requieren conocimiento, ni siquiera rudimentario, del derecho canónico ${ }^{68}$.

Alguna doctrina es bastante crítica en lo dispuesto en el m.p. al asignar estas funciones de fuerte contenido jurídico a personas sin preparación. Y esto, aun teniendo en cuenta lo dispuesto en el art. $8 \$ 1 \mathrm{RP}$ : «en las diócesis que no tengan tribunal propio, el Obispo preocúpese de formar cuanto antes -también mediante cursos de formación permanente y continua, promovidos por las diócesis o sus reagrupamientos, y por la Sede Apostólica en comunión de intenciones- a personas que puedan prestar su labor en el tribunal para las causas matrimoniales que se puedan constituir». La formación canonística no se improvisa; no es simplemente aplicar unas normas técnicas, sino un sentir con la Iglesia ${ }^{69}$.

Por esto, si se tiene en vista la futura tramitación de la causa, las personas que deben llevar a cabo la investigación deberían tener alguna especialización jurídica. No parece que el párroco o el sacerdote que los haya casado sea una persona idónea de por sí para este estudio jurídico, aunque sí para la labor de cercanía y apoyo espiritual y moral a los cónyuges ${ }^{70}$ : hay un cierto contrasentido confiar la investigación prejudicial a los que han preparado a los contrayentes a un «matrimonio valido y lícito» ${ }^{71}$. Quizá, como ya hemos indicado, en toda esta fase previa al proceso la intervención de los agentes de pastoral deberá ser cumulativa y sucesiva: las soluciones concretas de cómo plantear en cada diócesis este servicio de asesoramiento pueden ser muy diversas y dependiendo de los recursos humanos que el Ordinario de lugar pueda tener para llevarlo a cabo.

Entonces, ¿quién debería llevar a cabo este asesoramiento jurídico? En primer lugar podríamos pensar en la posibilidad de actuación de aquellos oficios diocesanos que están predispuestos para llevar la función judicial: el vicario judicial, el promotor de justicia, el defensor del vínculo y otros jueces eclesiásticos. También podrían preverse, como estaba indicado en el art. 113 DC, los abogados estables para esta labor: sería muy recomendable que al extenderse a todas las diócesis la existencia del tribunal diocesano, se cumplan las

\footnotetext{
${ }^{68}$ A primera vista, esto se podría ver comprensible ante la imposibilidad de reunir equipos en todas las diócesis (y en añadidura en las parroquias) y que la implantación de este servicio debería hacerse gradualmente.

${ }^{69}$ Cfr. G. BONI, La recente riforma..., cit., parte terza, 56-57.

$70 \ll$ Riteniamo che l'intervento dei parroci sia inderogabile perché legato all'ordinaria cura animarum ad essi affidata, ma ben si coniughi con un ulteriore e più incisivo intervento di supporto e aiuto»: M. DEL POZZO, Il processo matrimoniale..., cit., 89 nt. 39.

${ }^{71}$ Cfr. G. BonI, La recente riforma..., cit., parte terza, 60.
} 
disposiciones de que hayan abogados estables, o al menos un elenco de abogados a los que los fieles puedan dirigirse. Pensamos que esta última solución sería la más oportuna: sacerdotes y laicos debidamente preparados para afrontar este asesoramiento jurídico.

Indudablemente, siendo la interposición de una demanda de nulidad el fin con que se puede concluir el de la investigación previa, conviene recordar que el conocimiento de la situación matrimonial en esta fase puede afectar a la imparcialidad propia de la función judicial y con la defensa de vínculo en el posible futuro proceso. El vicario judicial, así como los otros jueces o ministros deberán evitar desarrollar las funciones de aconsejar o dar indicaciones que puedan poner en tela juicio su futura labor judicial (art. $113 \$ 2 \mathrm{DC}$ ). Esto se deberá tener en cuenta ante la carencia de personal especializado en muchas partes del orbe católico, para no desnaturalizar los principios del proceso justo ${ }^{72}$. En este sentido, también el Obispo debe saber conjugar la exhortación que realiza el art. $1 \mathrm{RP}$ en su responsabilidad directa pastoral en relación a los cónyuges en dificultad: piénsese en los casos de un futuro proceso brevior, su solicitud pastoral no debería comprometer la independencia del juicio y, por supuesto, no puede dar a entender una anticipación indebida o asegurarla del éxito de la instancia de nulidad $^{73}$.

\subsection{La estructura diocesana de asesoramiento}

Además de la labor que pueda realizar el párroco y otros agentes pastorales designados por el Obispo en su acompañamiento y acción pastoral a estas familias heridas, el m.p. ha previsto una forma específica de auxilio y con-

72 Cfr. G. BonI, La recente riforma..., cit., parte terza, 59-60; J. LlObELL, Alcune questioni comuni ai tre processi per la dichiarazione di nullità del matrimonio previsti dal m.p. «Mitis iudex», Ius Ecclesiae 28 (2016) 27.

73 «Il MI non regola, senza intaccare però la loro vigenza, alcune delle classiche manifestazioni di tutela dell'imparzialità giudiziale, come l'obbligo dell'astensione o la possibilità della ricusazione del giudice e degli altri ministri del tribunale (cfr. cann. 1449-1451 e DC artt. 68-70), fra i quali devono essere inclusi l'istruttore e l'assessore del nuovo processus brevior (cfr. MI can. 1685). Le RP del MI dedicano ampio spazio alla personale sollecitudine pastorale del Vescovo diocesano e dei parroci verso i fedeli in difficoltà matrimoniale (cfr. artt. 1-5). Un tale intervento del Vescovo diocesano in questa fase pastorale pregiudiziale intaccherebbe a priori la possibilità del processus brevior davanti al Vescovo diocesano, che infatti potrebbe essere ricusato qualora non si astenesse da giudicare? (...) Forse, l'obbligo di astenersi e il diritto a interporre la ricusazione potrebbero esistere dinanzi a circostanze particolarmente oggettive e non legate all'operato pastorale del Vescovo, quale potrebbe darsi se uno dei coniugi fosse suo parente»: J. LLOBELL, Alcune questioni comuni..., cit., 26. 
sejo: una estructura fija y orgánica en la diócesis ${ }^{74}$. Así lo enmarca el art. 3 RP, previendo posibilidad y grados de actuación en esta labor pastoral y de consejo, que podrán ser cumulativas y/o sucesivas en cuanto a la especialización y cualificación. De esta manera, el legislador prevé una forma de acompañamiento y acogida preliminar (paciente y cuidada), pero deja abierta e indeterminada la modalidad concreta y el nivel de complejidad en su aplicación: de la forma más simple e inmediata se puede llegar a una entidad más completa y $\operatorname{organizada}^{75}$. Se trata en definitiva de un servicio integrado en la pastoral matrimonial diocesana (art. $2 \mathrm{RP}$ ), en el que el tiempo y la praxis ayudarán a definir mejor el estatuto del instituto. Como ya se indicó, esta estructura consultiva tiene su antecedente en el servicio que en cada tribunal debía haber para aconsejar sobre el modo de proceder en las causas de nulidad del art. 113 $\$ 1$ DC, y que tenía un fin y alcance más limitado. En la nueva regulación, se ha delimitado, aunque sea sumariamente, un servicio más caracterizado y amplio: también las ciencias humanas y médicas pueden ofrecer una aportación significativa en la acogida y acompañamiento de los cónyuges. Esta estructura estable añade al encargo personal de acompañamiento pastoral la posibilidad de ofrecer un amplio asesoramiento (jurídico, médico, de mediación), y de la competencia específica de las personas que lo realizan. Por esto, la estructura estable podrá estar integrada por personal de diversos sectores (sacerdotes, canonistas, psicólogos, psiquiatras, consultores familiares, etc.). La previsión de un Vademécum indica no sólo la exigencia de modular y diferenciar localmente la operatividad del órgano, sino la integración y la maduración de la praxis y del trabajo en equipo realizado conjuntamente ${ }^{76}$.

Según la norma, la estructura puede ser diocesana o interdiocesana, lo cual evidencia la especialización y profesionalidad requerida. La preferencia por la organización diocesana de la justicia para conocimiento de las causas de nulidad matrimonial no excluye en este ámbito soluciones conjuntas y participadas por varias diócesis. Se podría pensar que a un tribunal interdiocesano corresponderá una estructura interdiocesana, aunque no se debe excluir la solución de que puedan darse estas estructuras a nivel diocesano con indepen-

$74 \ll$ Occorre ribadire che nella mens Legislatoris il ruolo consultivo pregiudiziale costituisce un profilo assai caratterizzante dello spirito e della lógica del nuovo proceso matrimoniale e non basta che sia assicurato in maniera un po'approssimativa e sbrigativa dai parroci»: M. DEL POZZO, Il processo matrimoniale..., cit., 91.

75 Cfr. P. Moneta, La dinamica processuale nel m.p. «Mitis Iudex», Ius Ecclesiae 28 (2016) 39-62.

${ }^{76}$ Cfr. M. DEL Pozzo, Il processo matrimoniale..., cit., 90. 
dencia del tribunal interdiocesano ${ }^{77}$, solución que sería más acorde con la mens Legislatoris, al señalar el Subsidio que el primer paso que los Obispos están llamados a realizar es la creación de este servicio ${ }^{78}$.

\section{CONTENIDO DE LA INVESTIGACIÓN PREJUdiCIAL Y REDACCIÓN DE UN VADEMÉCUM}

Aunque sea reiterar sucintamente la normativa de la RP, conviene recordar que, según el art. 2, la investigación prejudicial se orienta a conocer la condición de los matrimonios en crisis y a recoger elementos útiles para la posible celebración del proceso judicial, ordinario o más breve; y en el art. 4, el Legislador advierte que se investigue si las partes están de acuerdo al pedir la nulidad. Además, las personas que están asesorando deberán ayudar a las partes en la redacción del libelo para presentar en el tribunal competente (art. 5), si es la forma con que se finaliza la investigación, indicando el caput nullitatis y las circunstancias de hecho, las pruebas y los documentos en los que se apoyan.

Este servicio de información, asesoramiento y mediación vinculado con la pastoral familiar que los Obispos están llamados a implementar en sus diócesis se enmarca bajo el prisma del acompañamiento. Así se indica en el Subsidio: «este camino de "acompañamiento" puede ayudar a superar las crisis matrimoniales de manera satisfactoria, pero también está llamado a verificar, en los casos concretos, la verdad de la validez o no del matrimonio y "a recoger elementos útiles para la eventual celebración del proceso judicial, ordinario o más breve"» ${ }^{79}$.

Como puede comprobarse, esta fase presenta una naturaleza abierta, con amplitud de fines y competencias: de un lado, estaría la parte más propiamente pastoral de acogida y acompañamiento espiritual, para llegar a un posible consejo jurídico sobre la situación de posible nulidad o no en el matrimonio. Los

77 «Por analogía con el carácter provisional de los tribunales interdiocesanos y a la luz de las aclaraciones aportadas por el SA, entendemos que la investigación prejudicial a este nivel tan sólo puede existir con carácter subsidiario, mientras no exista en la diócesis el personal debidamente preparado para ello. Por tanto, el ámbito propio de actuación para este munus consulendi preiudicialis es el nivel diocesano. Ello no es óbice para que cada comunidad parroquial -empezando por el propio párroco (RP 3)-, en la medida en que disponga de personal cualificado, trabaje en coordinación con el organismo diocesano competente para facilitar la realización de la indagación prejudicial»: P. A. MORENO GaRCÍA, El servicio de indagación..., cit., 78.

78 Cfr. Tribunal Apostólico de la Rota Romana, Subsidio, 13.

${ }^{79}$ Cfr. ibid., 14. 
que intervienen en esta fase han de tener una idea clara y precisa de lo que se busca y pretende, y del campo de acción donde se deben mover, puesto que si no fuera así, se correría el peligro de que se extralimiten en sus funciones.

Esto tiene su importancia en la última fase, la que trata de los aspectos propiamente jurídicos: el investigador debe tener en cuenta que su labor no tiene la finalidad de realizar una instrucción judicial (en la que se debe guardar las garantías procesales que conlleva) y que, por tanto, su labor nunca deberá llegar a solaparse e interferir con la instrucción judicial propiamente dicha, que sólo puede realizarse dentro del proceso; situación que si se produjera en algún caso, sería preocupante y grave ${ }^{80}$. Esto podría suceder en la labor de documentación que el asesor judicial debe realizar: en las conversaciones con las partes y con los testigos, a las fáciles intromisiones y lesiones en la intimidad de las relaciones personalísimas de los cónyuges, a la violación de la privacidad de datos sensibles salvaguardados por las leyes civiles (que en muchas ocasiones están protegidas con sanciones) y que no basta con llevarlas a cabo con la humanidad y discreción cristiana de buena voluntad ${ }^{81}$. Por ejemplo, esta buena voluntad no es suficiente para identificar y valorar las circunstancias enunciadas de modo ejemplificativo en el art. $14 \mathrm{RP}$ para emprender el proceso brevior ${ }^{82}$.

Estos motivos son los que hacen muy necesario la redacción de un Vademécum ${ }^{83}$ para dar unidad y criterio en la actuación de todas las personas de esta fase (art. $3 \mathrm{RP}$ ), especificando con más o menos detalle los pasos a dar y los elementos fácticos que se deberán buscar, para poder ofrecer efectivamente un consejo canónico acertado. Como aclara el Subsidio, «las Conferencias Episcopales organizarán un Vademécum para garantizar la organización y la uniformidad de los procedimientos, con particular atención al desarrollo de la investigación pastoral» ${ }^{84}$.

${ }^{80}$ Cfr. G. BonI, La recente riforma..., cit., parte terza, 58.

81 «Por último, puesto que se trata de indagar en cuestiones delicadas, conviene que la persona responsable de la investigación prejudicial sea una sola, actuando bajo juramento de preservar el secreto profesional que concierne a su tarea. Obviamente, esa persona responsable podrá -con el consentimiento del solicitante- pedir la colaboración de las personas que considere oportunas para llevar a cabo esa labor»: P. A. Moreno GARCía, El servicio de indagación..., cit., 74.

82 Como ya hemos observado, el investigador debe desarrollar su trabajo con la debida competencia técnica.

83 Algunas propuestas para desarrollar este Vademécum pueden verse en P. A. MorENO GARCíA, El servicio de indagación..., cit., 78-82.

${ }^{84}$ Cfr. Tribunal Apostólico de la Rota Romana, Subsidio, 11-12. 
En líneas generales, la Conferencia Episcopal deberá valorar y sopesar el contenido de este Vademécum teniendo en cuenta que deberá responder a estas dos acciones ${ }^{85}$ :

a) de una parte, los criterios pastorales de acogida, acompañamiento espiritual, medios pastorales a aplicar también con vistas a una posible reconciliación o convalidación del matrimonio, dando libertad a los párrocos, sacerdotes y otros agentes de pastoral que están en contacto directo con estas personas (la persona que asesora escuchará el relato del cónyuge o cónyuges, para sacar a la luz los motivos de la crisis matrimonial). En esta fase también podrán intervenir especialistas en la mediación matrimonial;

b) de otra, señalar unas líneas claras de lo que se debe «buscar» en esa investigación prejudicial; si no, difícilmente se podrá asesorar la persona encargada por el Ordinario, especialmente necesario en los casos que sea realizada por alguien no experto en derecho canónico ${ }^{86}$. Para ello, se ha de explicar cómo se recopilan las pruebas necesarias en las que se funda una nulidad (documentos, testigos, etc.) porque es un trabajo técnico, como el que desarrolla el abogado a instancia de parte para dar una respuesta a su cliente sobre estos asuntos. Su labor puede finalizar con la ayuda a la elaboración de la demanda y a la presentación ante el tribunal competente.

\section{CONSIDERACIONES SOBRE LA EFICACIA JURÍDICA Y EL VALOR JURÍDICO}

\section{DEL ASESORAMIENTO}

La conclusión de la fase prejudicial es doble: a) una evaluación de los datos que lleven al investigador a no apreciar signos de nulidad matrimonial y

${ }^{85}$ Un ejemplo interesante de lo que se podría constituir en ámbito diocesano es el de la Oficina diocesana para la acogida de los fieles separados de la diócesis de Milán, cuya misión se formula como acompañar a los matrimonios (o del cónyuge que se presente) con el fin de ayudarles en la comprensión de su situación en sus aspectos morales y canónicos, para posteriormente intentar realizar una serie de funciones como posible reconciliación y mediación, así como una eventual convalidación del matrimonio; ayuda médica y psicológica; asesoramiento jurídico si es solicitado por ellos. Esta oficina se relacionará con los párrocos, consultores familiares diocesanos, patronos estables del tribunal, personal médico, etc. necesarios para la atenta ayuda espiritual y humana que requieren los fieles. Cfr. Ufficio diocesano per l'accoglienza dei fedeli separati, http://www.chiesadimilano.it/cms/2.662/struttura-persone/2.1293/ufficio-diocesano-per-l-accoglienza-dei-fedeli-separati/articoli/presentazione-1.114252.

${ }^{86}$ Cfr. E. ZANETTI, La consulenza previa..., cit., 14-15. Es muy importante la designación del abogado que deberá presentar la demanda y realizar los demás trámites procesales. 
por tanto no aconseja presentar una demanda; b) la estimación de que existen esos indicios de nulidad y, en este supuesto, si los contrayentes solicitan su intervención, les ayudará a la redacción y presentación de la demanda ante el tribunal competente, dando paso a la fase propiamente procesal con el examen de admisión de la demanda por el Vicario judicial (cc. 1676 y 1684), el cual comprobará si existen los requisitos procesales necesarios y que la petición contiene fumus boni iuris.

Hasta la actual reforma, las demandas estaban redactadas por los abogados de las partes, ya sean de libre elección o escogidos de los patronos estables de la lista del tribunal, sin que la autoridad de la Iglesia o su personal judicial se inmiscuyera en los trámites anteriores a la presentación de la demanda, entre los que estaba la recopilación de las posibles pruebas (documentos, testigos, pericias, etc.) y la redacción y presentación de la demanda. Al diseñar esta nueva fase prejudicial y pastoral el Legislador ha modificado en parte esta posición: su mens es que los agentes pastorales se impliquen directamente, también en la parte propiamente jurídica, y, si fuera necesario, su ayuda deberá llegar hasta la presentación de la demanda.

Esta nueva realidad, si es mal comprendida por los agentes pastorales, puede comportar una serie de riesgos. En primer lugar, podría llevar a las partes a pensar que sería muy beneficioso para sus pretensiones pasar por esta fase, ya que una vez dirigida la solución a una demanda de nulidad a través de las estructuras diocesanas ad hoc, podría dar la apariencia de que la Iglesia ha dado un paso en reconocer la existencia de dicha nulidad en su matrimonio. En efecto, las partes han trabajado con una persona o personas pertenecientes a la pastoral matrimonial y judicial diocesana, con los que se ha comprobado el fracaso matrimonial, la falta de éxito en la mediación, la existencia de elementos de una posible nulidad, se han adquirido pruebas (testigos, documentos, etc.) en las que se funda la nulidad, se ha redactado la demanda y se «presenta» todo este trabajo a la autoridad judicial oportuna (Obispo o Vicario judicial) para su valoración final ${ }^{87}$.

Por otra parte, puede producirse una falsa valoración jurídica al trabajo realizado; es decir, queremos plantearnos cuál es la valoración jurídica que tiene esta investigación prejudicial realizada en el ámbito de la es-

${ }^{87}$ Piénsese, por ejemplo, en el supuesto de una demanda que, tras pasar por la fase prejudicial, se orienta por parte de los asesores diocesanos hacia el proceso brevior del c. 1684: para las partes, la apariencia del fundamento de nulidad es fuerte. 
tructura diocesana (con la posible carga de oficialidad que tiene el que participen personas que trabajan en oficios eclesiásticos) y si es diversa a lo que sucedía hasta ahora en la aceptación de la demanda. O incluso, se nos permita la pregunta, si tendría distinta eficacia con las causas actuales cuyas demandas son interpuestas directamente por las partes sin pasar por esta fase $^{88}$.

Adelantamos que nuestra respuesta es que no tiene especial influencia jurídica, diversa a la de cualquier demanda, haya pasado o no por esta fase; es decir, las conclusiones de la investigación prejudicial tienen un carácter orientativo para los fieles a la hora de presentar o no la demanda de nulidad, y no son vinculantes para los jueces en orden a su admisión o rechazo ${ }^{89}$. Esta conclusión se desprende de:

a) la labor que realiza el Vicario judicial para aceptar la demanda no ha sido modificada por la nueva legislación (para el proceso ordinario c. 1676, para el proceso brevior cc. 1684 1685);

b) esta investigación es un servicio facultativo puesto a disposición de los fieles, pero éstos no tienen por qué pasar necesariamente por él para introducir la demanda de nulidad (ver lo indicado supra, apartado n. 4.1. sobre la obligatoriedad del servicio pastoral como posible paso previo requisito a la demanda);

c) que el juez deberá dictar sentencia al alcanzar la certeza moral de lo alegado y probado dentro del proceso (c. 1608). El trabajo previo a la aceptación de la demanda, realice quien lo realice, no tiene el valor de prueba judicial en sentido jurídico: esos testimonios, documentos, etc., de nuevo deberán ser presentados esta vez ante el juez para su valoración, además de que debe existir siempre el contradictorio entre las partes $^{90}$.

${ }^{88}$ También podría darse el peligro de un falso pastoralismo por parte de la autoridad eclesiástica al dar mayor peso a las demandas que procedieran de esta investigación pastoral, en la que el Obispo o el juez prejuzgaran ya su decisión final hacia la nulidad matrimonial. Esto no debería suceder, aunque si se hace bien la investigación prejudicial, lógicamente facilitará la tramitación de la causa como puede suceder cuando se presenta la demanda (con sus pruebas) por un buen abogado.

89 Cfr. P. A. Moreno García, El servicio de indagación..., cit., 71-72.

${ }^{90}$ Cfr. M. J. Arroba Conde, La pastoral judicial..., cit., 76. Esto mismo sucede en ámbito penal, cuya investigación previa está protegida y delimitada por la actuación del Ordinario: si decide ir al proceso penal, entregará las actas de la investigación al Promotor de justicia para que éste presente el escritorio acusatorio (cfr. c. 1721). 


\section{CONCLUSIÓN}

En el estudio hemos querido resaltar algunos aspectos de la nueva legislación referente a la puesta en marcha del servicio de consulta de la así denominada investigación prejudicial o pastoral. Como afirma la norma, esta investigación mira a acoger y prestar específica atención a los fieles en dificultad: su fin no es la preparación inmediata y directa del proceso, sino el discernimiento acerca de la posible validez del matrimonio. Nos parece impropio y reductivo presentar la investigatio como la recogida de datos e indicios en vista a la futura demanda. Hasta el momento, algunas de las definiciones que se han propuesto de esta fase o quedan demasiado encerradas en resaltar el aspecto jurídico de la posible presentación de la demanda ${ }^{91}$, o no acaban de resaltar toda la potencialidad que puede aportar esta fase ${ }^{92}$.

Por nuestra parte pensamos que en la mente del Legislador, la pastoralidad y eficacia de la cura de almas en las familias heridas por el fracaso matrimonial (en un sentido amplio, no quedándose reducidas a los separados y divorciados), así como del mismo servicio judicial al que podrían acceder, están basadas principalmente en el acompañamiento pastoral que se debe realizar y en la investigación prejudicial de asesoramiento: en primer lugar comprensión humana y espiritual hacia las personas que han conocido la ruptura del propio matrimonio, con el fin de hacer experimentar la maternidad de la Iglesia; y

${ }^{91}$ «La investigación prejudicial o pastoral, es una labor facultativa; desplegada a instancia de parte por un órgano competente; mediante un acto administrativo; por personas u órganos competentes; para recopilar ("colligatur") los elementos de juicio que permitan efectuar o desestimar una intimación clara, precisa y circunstanciada. Es decir, para determinar si existe mérito suficiente para incoar un procedimiento matrimonial útil»: F. J. REGORDÁN, La investigación prejudicial en las nuevas normas procesales del M. P. Mitis Iudex Dominus Iesus, XIII Conversaciones Canónicas Valentinas. «Mitis Iudex Dominus Iesus»: algunas cuestiones en torno a la reforma de los procesos de la nulidad matrimonial, Valencia, 8-10 de febrero de 2016, Anuario de Derecho Canónico, suplemento 5 (2016) 43.

92 «A la vista de las ulteriores aportaciones del Tribunal de la Rota Romana mediante el SA, nos atrevemos a aportar unos rasgos definitorios que puedan servir de complemento a la formulación anterior: la indagación prejudicial es un servicio cualificado y facultativo, creado en el ámbito de la pastoral matrimonial unitaria por el Obispo diocesano, quien muestra su solicitud hacia todos los que se hallan separados o divorciados y se cuestionan la existencia de su vínculo matrimonial, ofreciéndoles los medios adecuados para tratar -en primer lugar- de superar la crisis conyugal y restablecer la convivencia, llevando a cabo -si fuera necesario- una convalidación del matrimonio; comprobada la imposibilidad de la reconciliación, la labor de este servicio se orienta a estudiar la viabilidad de un proceso de nulidad matrimonial, recogiendo los elementos útiles para ello y -tras verificar la existencia del requerido fumus boni iuris- culmina con la redacción del libelo de demanda para ser presentado ante el tribunal competente»: P. A. MORENO GARCÍA, El servicio de indagación..., cit., 72. 
sólo posteriormente, verificar la verdad de la validez o no del matrimonio y posibles caminos a seguir como reconciliación de los cónyuges, posible convalidación del matrimonio, presentación de demanda de nulidad, etc. (su rol es simplemente de consejo y de mediación). Por este motivo, la Iglesia desea que se implemente este servicio en cada diócesis.

Para ello, el Obispo es responsable de la previsión de posibles instrumentos adecuados y establecer las medidas de asistencia y consulta necesarias para ofrecer a sus fieles este servicio de asesoramiento. La nueva legislación delinea de una manera abierta y variable toda esta función y la posible estructura que se constituya en las diócesis. De esta forma, al Obispo se le proporciona una gran libertad para desarrollar su labor, pero también se le pide una gran dosis de iniciativa y creatividad: escoger los modos y las formas más convenientes para llevar a cabo la pastoral familiar diocesana en este sector de emergencia y crisis $^{93}$. Según la normativa esta función de consejo puede venir a través de una duplicidad de formas o niveles, que pueden ser cumulativos o sucesivos, también en lo que se refiere a la cualificación y especialización de los mismos: un encargo personal y una estructura estable diocesana.

En relación al encargo personal, se señala un doble criterio en la elección del agente pastoral: el propio párroco o el que preparó a los cónyuges para la celebración de la boda, a los que se pueden añadir otros clérigos, consagrados o laicos aprobados por el Ordinario del lugar. La referencia en primer lugar al párroco implica una segura garantía de acogida y sobre todo que se cumplirá la exigencia de una sensibilidad pastoral antes de que se inicie un proceso judicial. Esta actuación del párroco no excluye soluciones posteriores más cualificadas. Por otra parte, la estructura diocesana añade al encargo personal de acompañamiento la posibilidad de ofrecer un amplio asesoramiento (jurídico, médico, de mediación), y de la competencia específica de las personas que lo realizan. Esta estructura podrá estar integrada por personal de diversos sectores: sacerdotes, canonistas, psicólogos, psiquiatras, consultores familiares, etc.

$\mathrm{Al}$ presentarse esta fase con una naturaleza abierta, con amplitud de fines y competencias, se ve conveniente la redacción de un Vademécum por parte de la Conferencia Episcopal, cuyo contenido debería incluir: a) los criterios pastorales de acogida, acompañamiento espiritual, medios pastorales a aplicar

93 «Linattuazione pratica del disposto non dimostrerebbe sicuramente troppa fedeltà e comunione con l'impostazione e la sensibilità della riforma processuale e del cammino sinodale»: M. DEL Pozzo, Il processo matrimoniale..., cit., 84. 
también con vistas a una posible reconciliación o convalidación del matrimonio, dando libertad a los párrocos, sacerdotes y otros agentes de pastoral que están en contacto directo con estas personas (la persona que asesora escuchará el relato del cónyuge o cónyuges, para sacar a la luz los motivos de la crisis matrimonial); b) las pruebas que se deben buscar en esa investigación prejudicial en las que se fundaría una nulidad (documentos, testigos, etc.), y la forma de llevarlo a cabo al tratarse de un trabajo técnico, como el que desarrolla el abogado a instancia de parte.

Éste es el principal desafío en el que se encuentran los Obispos: asegurar la pastoralidad de la acogida (acompañamiento) y, a su vez, garantizar el interés y la profesionalidad científica-canónica en la eventual comprobación de las circunstancias del matrimonio. Esto reclama un decidido cambio cultural y de mentalidad en los Obispos y en todos aquellos que intervienen en este proceso. La mejor garantía para el fiel cumplimiento de la reforma se confía a la formación del personal que requiere: una puesta al día en la competencia técnico y pastoral de los actuales ministros de los tribunales, así como la formación y promoción de jóvenes juristas y consultores familiares ${ }^{94}$. Flaco servicio se realizaría si, en vez de mejorar los niveles de profesionalidad de las personas que se ocupan de estos campos, la reforma se quedara en un simple facilitar el acceso a estas funciones a personas técnicamente mal o poco preparadas.

${ }^{94}$ Cfr. M. DEL Pozzo, L'organizzazione giudiziaria..., cit., 33. 


\section{Bibliografía}

ARroba Conde, M. J., La pastoral judicial y la preparación de la causa en el motu proprio m.p. «Mitis Iudex Dominus Iesus», en M. E. Olmos OrTega (ed.), Procesos de nulidad matrimonial tras las reforma del papa Francisco, Dykinson, Madrid 2016, 63-82.

BEAL, J. P., «Mitis Iudex» Canons 1671-1682, 1688-1691: A Commentary, The Jurist 75 (2015) 467-538.

BonI, G., La recente riforma del processo di nullità matrimoniale. Problemi, criticità, dubbi (parte terza: $\$ S 5$ 5-7), Stato, Chiese e pluralismo confessionale. Rivista telematica (http://www.statoechiese.it/ 21 marzo 2016), 11/2016.

Bunge, A. W., Presentación del nuevo proceso matrimonial, en http://www.awbunge.com.ar/OtrosCursos.html.

Del Pozzo, M., sub art. 113 DC, en M. Del Pozzo - J. Llobell - J. MiNAMBRES (eds.), Norme procedurali canoniche commentate, Coletti a San Pietro, Roma 2013, 374-375.

—, L'organizzazione giudiziaria ecclesiastica alla luce del m. p. «Mitis iudex», Stato, Chiese e pluralismo confessionale. Rivista telematica (http://www.statoechiese.it/ 23 noviembre 2015), 36/2015.

—, Il processo matrimoniale più breve davanti al Vescovo, Edusc, Roma 2016.

Díaz Moreno, J. M., Anotaciones personales sobre el «servicio de orientación jurídica», en J. OTADUY (ed.), Nuevas situaciones, nuevas leyes, nuevas respuestas (Actas de las XXIX Fornadas de Actualidad Canónica organizadas por la Asociación Española de Canonistas en Madrid, 15-17 de abril de 2009), Dykinson, Madrid 2010, 191-207.

ERRÁZuRIZ M., C. J., Licitud moral de la presentación de la demanda de nulidad matrimonial por los esposos, Ius Canonicum 41 (2001) 169-189.

García Montagud, J., El nuevo servicio de orientación jurídica de los Tribunales Eclesiásticos, en J. OTADUY (ed.), Nuevas situaciones, nuevas leyes, nuevas respuestas (Actas de las XXIX Fornadas de Actualidad Canónica organizadas por la Asociación Española de Canonistas en Madrid, 15-17 de abril de 2009), Dykinson, Madrid 2010, 161-189.

LlOBELl, J., Alcune questioni comuni ai tre processi per la dichiarazione di nullità del matrimonio previsti dal m.p. «Mitis iudex», Ius Ecclesiae 28 (2016) 13-38.

—, Los procesos matrimoniales en la Iglesia, Rialp, Madrid 2014.

Maragnoli, G., sub art. 122 DC, en M. Del Pozzo - J. Llobell - J. MiÑAMBRES (eds.), Norme procedurali canoniche commentate, Coletti a San Pietro, Roma 2013, 384-385. 
Moneta, P., La dinamica processuale nel m.p. «Mitis Iudex», Ius Ecclesiae 28 (2016) 39-62.

Morán, C., El proceso brevior ante el Obispo diocesano, en M. E. Olmos OrTEGA (ed.), Procesos de nulidad matrimonial tras las reforma del papa Francisco, Dykinson, Madrid 2016, 125-175.

-, Retos de la reforma procesal de la nulidad del matrimonio, Ius Canonicum 56 (2016) 9-40.

Moreno García, P. A., El servicio de indagación prejudicial: aspectos jurídicopastorales, Ius Canonicum 56 (2016) 65-85.

Mosconi, M., Il nuovo «Ufficio diocesano per l'accoglienza dei fedeli separati» dell'Arcidiocesi di Milano, Ius Ecclesiae 27 (2015) 716-730.

Nieva García, J. A., Reforma del proceso canónico para la declaración de nulidad del matrimonio y pastoral de los fieles divorciados y vueltos a casar, Universidad San Dámaso, Madrid 2015.

PeÑa, C., Agilización de los procesos canónicos de nulidad matrimonial: de las propuestas presinodales al motu proprio Mitis Iudex Dominus Iesus y retos pendientes tras la reforma, Ius Canonicum 56 (2016) 41-64.

PeÑa Vial, J., Fidelidad y amor conyugal a la luz de la Constitución Gaudium et Spes, Scripta Theologica 48 (2016) 79-92.

REgORDÁN, F. J., La investigación prejudicial en las nuevas normas procesales del M. P. Mitis Iudex Dominus Iesus, XIII Conversaciones Canónicas Valentinas. «Mitis Iudex Dominus Iesus»: algunas cuestiones en torno a la reforma de los procesos de la nulidad matrimonial, Valencia, 8-10 de febrero de 2016, Anuario de Derecho Canónico, suplemento 5 (2016) 39-52.

RinCÓN-PÉREZ, T., sub cc. 1066-1068, en Comentario exegético al Código de Derecho Canónico, III/2, Eunsa, Pamplona 32002, 1121-1124.

RodrígueZ-OCAÑA, R., La demanda judicial canónica, Navarra Gráfica Ediciones, Pamplona 2002.

—, sub c. 1505, en Comentario exegético al Código de Derecho Canónico, IV/2, Eunsa, Pamplona ${ }^{32002,1200-1209 .}$

—, «Admisión a la demanda», en J. Otaduy - A. Viana - J. SEDANo (eds.), Diccionario General de Derecho Canónico, vol. I, Aranzadi, Pamplona 2012, 250-252.

—, Nueva regulación de los procesos de nulidad matrimonial, Scripta Theologica 48 (2016) 295-331.

SanchIS, J., sub cc. 1717-1719, en Comentario exegético al Código de Derecho Canónico, IV/2, Eunsa, Pamplona 32002 , 2062-2074. 
Tribunal Apostólico de la Rota Romana, Subsidio aplicativo del Motu pr. Mitis Iudex Dominus Iesus, Ciudad del Vaticano, enero 2016.

ZAMBON, A., La presentazione del libello, en La Riforma dei processi matrimoniali di papa Francesco. Una guida per tutti, Quaderni di diritto ecclesiale, Ancora Editrice, Milano 2016, 29-46.

ZANETTI, E., La consulenza previa all'introduzione di una causa di nullità matrimoniale, en La Riforma dei processi matrimoniali di papa Francesco. Una guida per tutti, Quaderni di diritto ecclesiale, Ancora Editrice, Milano 2016, 9-27. 